\title{
Platelet volume evaluation in patients with sepsis: associated factors should be considered
}

\author{
Ercan Varol
}

Department of Cardiology, Faculty of Medicine, Suleyman Demirel University, Isparta, Turkey

Key words: Mean platelet volume, Sepsis

African Health Sciences 2014; 14(2):492-493

DOI: http://dx.doi.org/10.4314/ahs.v14i2.32

I have read the article published by Guclu et al. with a great interest. ${ }^{1}$ They examined platelet indices in patients with sepsis. Mean platelet volume (MPV) and platelet distribution width (PDW) were significantly higher in patients with sepsis than in controls. MPV and PDW were significantly higher in patients with severe sepsis than in patients with sepsis. This is very interesting study with large sample size. On the other hand, I want to mention minor criticism about this study from methodological aspect.

Firstly, methods section is not clear and they did not mention about the tube that the blood sample was collected for platelet indices and time interval between blood sampling and analysis. This is very important. It is clear that platelets exhibit a time-dependent swelling when blood samples are anticoagulated with ethylenediaminetetraacetic acid (EDTA), while this swelling does not occur in the presence of citrate. ${ }^{2,3} \mathrm{With}$ impedance counting, the MPV increases over time as platelets swell in EDTA, with increases of $7.9 \%$ within $30 \mathrm{~min}$. Although an overall increase of $13.4 \%$ occur over $24 \mathrm{~h}$ the majority of this increase occurs within the first 6 h. ${ }^{4}$ The recommended an optimal measuring time of MPV is 120 min after venipuncture. ${ }^{5}$ For reliable MPV measurement, the potential influence of anticoagulant on the MPV must be carefully controlled, either using an alternative anticoagulant (such as citrate) or standardizing the time delay between sampling and analysis (less than $2 \mathrm{~h}$ ).

\section{Corresponding author:}

Suleyman Demirel

Univesitesi Tip Fakultesi, Isparta, Turkey

Tel.: +90 5323468258; fax: +90 2462324510

E-mail address: drercanvarol@yahoo.com
This situation is not clear in study.

Secondly, there are significant associations of MPV with type 2 diabetes mellitus, prediabetes, smoking, hypertension, hypercholesterolemia, obesity, coronary heart disease, metabolic syndrome, statin and some antihypertensive use and atrial fibrillation. ${ }^{6}$ They did not mention about these confounding factors in patients and control subjects. It is evident that type 2 diabetes mellitus, prediabetes, smoking, hypertension, hypercholesterolemia, obesity, coronary heart disease and metabolic syndrome increase MPV. ${ }^{6}$

MPV is universally available with routine blood counts by automated hemograms and a simple and easy method of assessing platelet function. In comparison to smaller ones, larger platelets have more granules, aggregate more rapidly with collagen, have higher thromboxane A2 level and express more glycoprotein Ib and IIb/IIIa receptors. ${ }^{2,6}$ We believe that MPV can be affected by many inflammatory and cardiovascular risk factors. If the authors had taken into account the above mentioned confounding factors, they might have found different results.

\section{References}

1. Guclu E, Durmaz Y, Karabay O. Effect of severe sepsis on platelet count and their indices. Afr Health Sci. 2013 Jun;13(2):333-8.

2. Bath PM, Butterworth RJ. Platelet size: measurement, physiology and vascular disease. Blood Coagul Fibrinolysis 1996; 7: 157-61.

3. Dastjerdi MS, Emami T, Najafian A, Amini M. Mean platelet volume measurement, EDTA or citrate? Hematology 2006; 11: 317-9

4. Bowles KM, Cooke LJ, Richards EM, et al. Platelet size has diagnostic predictive value in patients with thrombocytopenia. Clin Lab Haematol. 2005;27:370-373. 
5. Lancé MD, van Oerle R, Henskens YM, et al. Do we need time adjusted mean

platelet volume measurements? Lab Hematol. 2010;16:2831.
6. Vizioli L, Muscari S, Muscari A. The relationship of mean platelet volume with the risk and prognosis of cardiovascular diseases. Int J Clin Pract. 2009;63(10):150915. Review. 